\title{
Sonophysically Exfoliated Individual Multi- Walled Carbon Nanotubes in Water Solution and their Straightforward Route to Flexible Transparent Conductive Films
}

\author{
Wen-Yin Ko, Jun-Wei Su and Kuan-Jiuh Lin \\ Department of Chemistry, National Chung-Hsing University, \\ Taiwan (ROC)
}

\section{Introduction}

Flexible transparent conducting films (TCFs) with low electric resistance and high optical transmittance have received considerable attention for niche applications such as flexible/foldable displays, touch screens, solar cells, transistors, and transparent electrodes for liquid crystal displays. (Calnan \& Tiwari, 2010; Gruner, 2006; Heo et al., 2010; Jo et al., 2010; Takenobu et al., 2006) Deposition of indium tin oxide (ITO) onto plastic substrates to prepare the flexible TCFs has been an attractive strategy owing to its transparency, conductivity, and wide usability. (D. H. Kim et al., 2006; Lin et al., 2008; $\mathrm{Na}$ et al., 2008; Sierros et al., 2009; Wang et al., 2008) Nevertheless, the flexible ITO-based TCFs still suffer from several drawbacks. For example, the films are often prepared under vacuum and high temperature conditions, resulting in the limitation of their suitability for many polymer substrates such as polyethylene terephthalate (PET), which are often used in flexible devices and touch screen panels. Also, ITO is expensive owing to the limited supply of indium; it is brittle and will crack under a $2 \%$ strain, resulting in loss of conductivity. Furthermore, the film transparency is poor in the near-infrared range. (Feng et al., 2010; Manivannan et al., 2010; Park et al., 2010) Therefore, a substitute for ITO is necessary.

To address this issue, carbon nanotubes (CNTs), because of their high flexibility, specific surface area, low density, and excellent electrical, optical, and mechanical properties, have been regarded as the most promising alternative. CNTs have a preeminent status in nanomaterials and have a huge range of potential applications. (Z. R. Li et al., 2007; Paul \& Kim, 2009; Simien et al., 2008) Single-walled CNT (SWCNT)-based conductors and semiconductors were used as the active material in the fabrication of flexible CNT-TCFs. Recent efforts towards the fabrication of SWCNTs on several substrates of glass, UV-ozone (UV-O3) treated glass, poly(styrenesulfonate) (PEDOT:PSS) coated glass, flexible PET films, and other substrates to form transparent conducting SWCNT films with sheet resistance and transparency equivalent to ITO have been attempted. These attempts used various approaches such as spin coating, spray coating, solution dipping where the SWCNTs were pre-formulated in combination with surfactants and polymers. (Chen et al.; Dan et al., 2009; Manivannan et al., 2010; Paul \& Kim, 2009; Saran et al., 2004; Xiao et al., 2010) However, the 
performance of SWCNT-based TCFs does not yet meet the industrial requirements because of their high cost and limited scalability. Furthermore, it is still difficult to purify and disperse SWCNTs in gas or liquid. To overcome these limitations, inexpensive multi-walled CNTs (MWCNTs) are required. A few methods for the fabrication of flexible TCFs using MWCNTs have been developed. (Feng et al., 2010; Kaempgen et al., 2005; Xu et al., 2008; Zhang et al., 2005) However, there are still only a few documented examples of the use of MWCNTs in the fabrication of flexible TCFs. This is because of the fact that MWCNTs selfaggregate into large bundles and ropes in aqueous solutions resulting from strong intertube van der Waals attractions (ca. $500 \mathrm{eV} / \mu \mathrm{m}$ ) (Girifalco et al., 2000). Such aggregation results in a decrease of their unique physical properties, especially in their optical transparency in the visible spectrum. (O. K. Kim et al., 2003; Paloniemi et al., 2005)

Currently two approaches are widely applied to promote dispersion of the MWCNTs - the mechanical approach and the functionalization approach. Unfortunately, both methods have significant drawbacks. The mechanical approach including ultrasonication and highshear mixing is a time-consuming, low-efficiency synthetic process and the stability of the resulting dispersion is poor. (Lu et al., 1996) The functionalization process involves the modification of the MWCNT surface with various surfactants and polymers by covalent and noncovalent methods. The covalent method, which involves the bonding of different chemical functional groups on the sidewalls of CNTs, can damage the structure of pristine nanotubes and alter their intrinsic properties. The noncovalent method, which involves adsorption of chemical moieties onto the surface of nanotubes via $\Pi-\Pi$ stacking interaction or coulomb attraction results in a suspension with poor long-term because of the weak interactions between the chemical moieties and the surface of CNTs. (D. Li et al., 2003; Madni et al., 2010; Marsh et al., 2007; Rastogi et al., 2008) To overcome the above mentioned problems, the main object of the present invention is to provide a method for the rapid dispersion of MWCNTs in solvents such that the desirable properties of carbon nanotubes are retained and the resulting suspension is stable and uniform for a long time. Another objective of the present invention is to provide an agent that can calibrate the concentration of the carbon nanotubes. Thus, in this chapter, we first propose a sonophysically exfoliated method with the aid of surfactants or polymers that produces a homogeneous MWCNTswater solution. Significantly, the resulting suspensions of water-soluble MWCNTs were homogeneous and the MWCNTs were uniformly dispersed for at least two years; neither sedimentation nor aggregation of nanotubes was observed. Furthermore, our sonophysically exfoliated method does not alter the crystalline and metallic electric properties; importantly, this dispersion is suitable for the determination of solubility and dispersion limits using concentration-dependent optical absorption spectrum. Next, porous MWCNT structures generated by ultrasonic atomization from a well-dispersed aqueous solution are spin-cast onto a poly(ethylene terephthalate) (PET) substrate to form a flexible conducting film (MWCNT-PET). Remarkably, the as-prepared film exhibits excellent sheet resistance, competitive transparency at $550 \mathrm{~nm}$, and remarkable flexibility compared to other related transparent conducting materials such as ITO and SWCNTs.

\section{Experimental detail}

\subsection{Synthesis and purification of MWCNTs}

MWCNTs, with average diameters of 10-30 nm and lengths of 5-15 $\mu \mathrm{m}$ were prepared from a mixture of ethylene $\left(\mathrm{C}_{2} \mathrm{H}_{4}\right)$ and methane $\left(\mathrm{CH}_{4}\right)$ by a high-temperature chemical vapor 
deposition (CVD) process using the First Nano-EasyTube 2000 system and iron oxide powder as a catalyst (Figure 1a). The produced MWCNTs were further purified by treatment with concentrated hydrochloric acid, followed by washing with water and precipitation, and then were dried under vacuum. The dried MWCNTS were subsequently heat treated in air at $400{ }^{\circ} \mathrm{C}$ to remove amorphous carbons. The purity thus achieved $>99$ $\mathrm{wt} \%$, as indicated by thermogravimetry analysis measurements (TGA, PERKIN ELMER TGA7792), shown in Figure 1b. Figure 1c represents the typical Raman spectrum of the asprepared MWCNTs before and after purification. These peaks appeared at approximately the same position for all samples in which three significant Raman fingerprints were determined: $D$-band at ca. $1323 \mathrm{~cm}^{-1}$, G-band at ca. $1578 \mathrm{~cm}^{-1}$, and $G^{\prime}$-band at ca. $2648 \mathrm{~cm}^{-1}$. A decrease in the $\mathrm{I}_{\mathrm{D}} / \mathrm{I}_{\mathrm{G}}$ ratio and an increase in the $\mathrm{I}_{\mathrm{G}^{\prime}} / \mathrm{I}_{\mathrm{G}}$ ratio for purified MWCNTs relative to the as-prepared ones were noticed, which is indicative of the decrease of impurities and enhancement of MWCNT quality. Besides, the extremely high intensity of the G'-band and the narrow FWHM of the G-band and G'-band in our result reflect the purified MWCNTs are pure with a high degree of crystalline perfection and retain their metallic property.
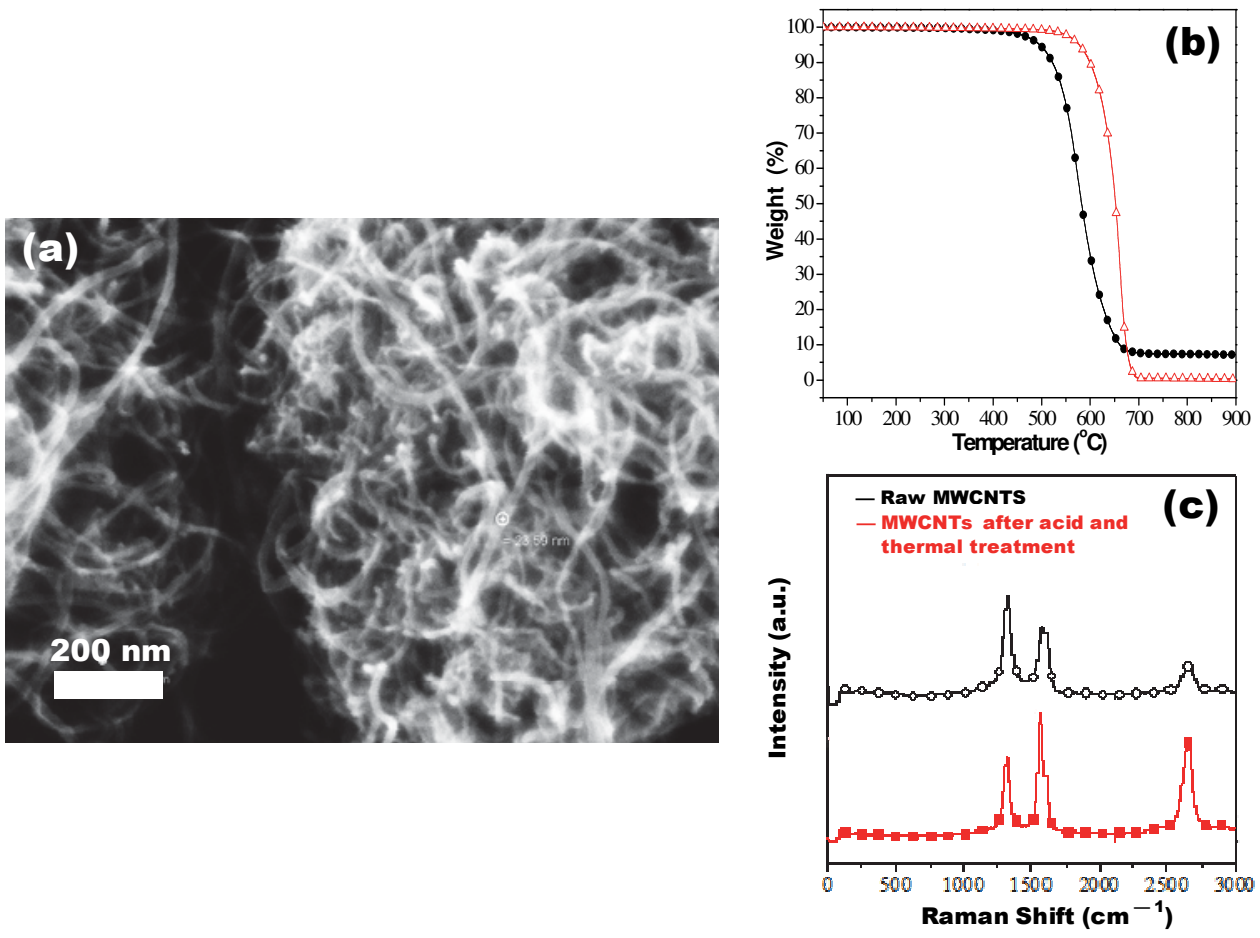

Fig. 1. (a) FESEM images of as-prepared MWCNTs by CVD, (b) TGA profiles, and (c) Raman spectra of MWCNTs with (red) and without (black) purification.

\subsection{Dispersion of MWCNTs}

In order to obtain a well-dispersed and homogeneous MWCNT-solution, we mixed 250 $\mathrm{mg} / \mathrm{L}$ MWCNTs into $500 \mathrm{mg} / \mathrm{L}$ aqueous solution in the presence of sodium dodecyl sulfate 
(SDS) surfactant and then sonicated the suspension using a probe type sonicator (SONICS® VCX750, supplied by Sonics \& Materials, Inc.) at $20 \%$ of the maximum power $(750 \mathrm{~W})$ for 5 minutes as well as at $39 \%$ of the maximum power for $5 \mathrm{~min}$ so as to prevent the aggregation of the MWCNTs. Initially, the processes of formation, growth, and implosive collapse of acoustic cavitation bubbles induced by the probe-type sonicator would generate the requisite energy at the CNT-CNT interface to cause individual CNTs exfoliation. (Su et al., 2009; Thiruvengadathan et al., 2007) Then, the SDS micelles wrap around the individual MWCNTs and prohibit the aggregation of the nanotubes thereby resulting in a stable and homogenous MWCNT aqueous suspension.
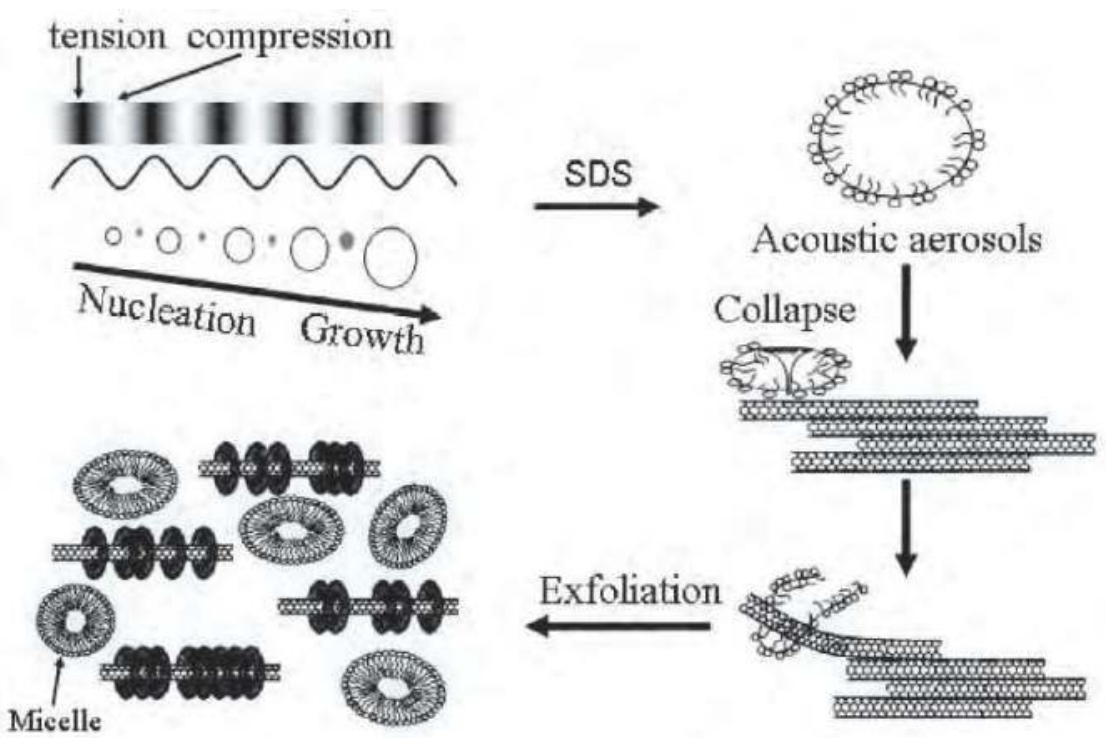

Fig. 2. Schematic of surfactant-assisted ultrasonication routes to carbon nanotube dispersion in aqueous solution.

\subsection{Fabrication of MWCNT-PET transparent thin films}

Polyethylene terephthalate (PET) substrates (3M, Transparency Film, Made in E.U. 0.10 mm, KB-9997-4219-4, $4 \times 4 \mathrm{~cm}$ ) were used in the present experiments. Ultrasonic atomization, a technique of producing a fine spray from a liquid, is a relatively inexpensive technique for the continuous production of micro- and nano-sized materials to assist the production of large-sized films by spin coating. It involves the generation and subsequent deposition of a mist of micron-sized droplets from a humidifier onto the surface of a substrate. Next, the water evaporated and the solute precipitated to form products. (Su et al., 2008) All the steps in the preparation of CNT-based TCFs were carried out using our designed ultrasonic atomization-spin coating equipment, as shown in Figure 3. For the fabrication of the MWCNT-PET conducting films, first, isolation of the MWCNTs is needed. This involves the formation of atomized particles ranging from 1 to $50 \mu \mathrm{m}$ in size including carbon nanotubes, prepared by the atomization of the homogeneous carbon nanotube solution $(10 \mathrm{mg} / \mathrm{L})$, which has a viscosity ranging from 1 to 50 c.p. The atomization was controlled by tuning the 
amount of SDS surfactants at room temperature at a supersonic atomizing frequency of 20 $\mathrm{KHz}-2.45 \mathrm{MHz}$ and atomizing rate of $25-30 \mathrm{~mL} / \mathrm{h}$ in an ultrasonic atomizer (Pro-Wave Electronic Corp M165D25). The frequency of the supersonic atomizing member for producing the atomized particles with desirable size can be determined from the following formula: (Miller, 1984)

$$
D=\alpha\left(\frac{8 \pi T}{\rho f^{2}}\right)^{\frac{1}{3}}
$$

wherein:

$\mathrm{D}$ is the particle size of the atomized particles;

$\mathrm{T}$ is a surface tension coefficient $(\mathrm{N} / \mathrm{cm})$;

$\rho$ is the density of the carbon nanotube solution;

$\mathrm{f}$ is the supersonic atomizing frequency; and

$a$ is a constant of 0.34 .

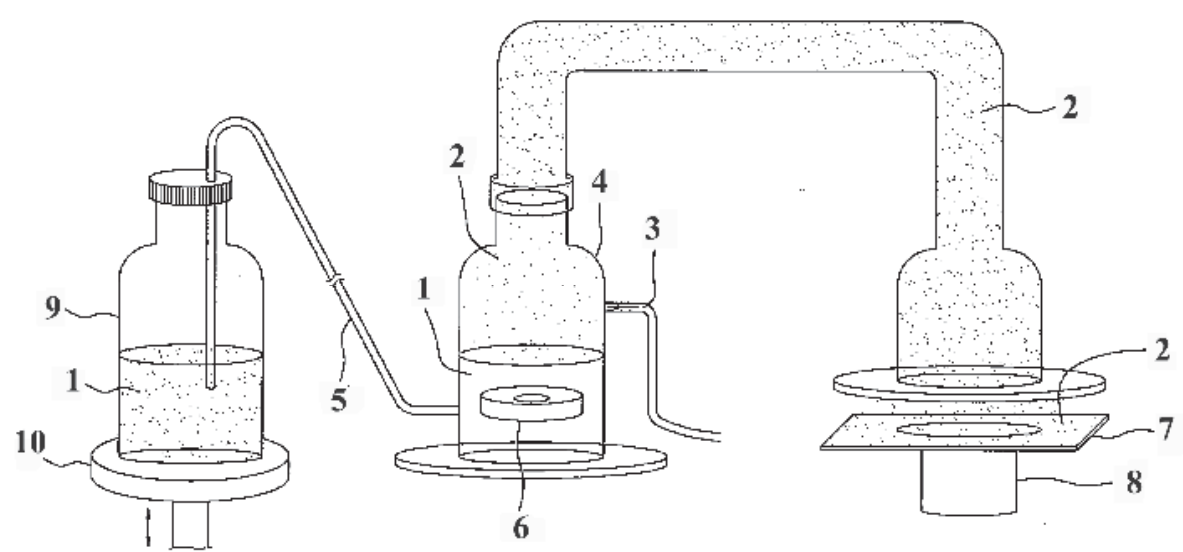

Fig. 3. Schematic view of our designed equipment that combines ultrasonic atomizer with spin-coating apparatus for fabricating conducting thin films. The CNT solution (1) is atomized at a supersonic atomizing frequency to form atomized particles of various sizes (2) including the CNTs. Specifically, (1) is contained in an atomizing container (4) and is maintained at a constant level using a siphon (5) that connects (4) with a reservoir (9). Thus, a supersonic atomizing member (6) that generates the supersonic atomizing frequency is maintained at a constant depth below the level of (1) to produce the atomized particles (2) of desirable particle size. (9) is placed on an elevating device (10). The level (1) in (4) can be controlled by adjusting the height of (10). Preferably, (9) can be provided with a probe type sonicator (not shown) to maintain a homogeneous dispersion of (1) in (9.) A carrier gas (3) is provided to carry (2) to a substrate (7) placed on spin coating equipment (8) for the formation of the conductive thin CNT films.

These atomized particles are transferred to spin-coating equipment with a carrier gas stream of nitrogen at a flow rate of $22 \mathrm{~L} / \mathrm{min}$ and then spin-coated onto PET films at a speed of 6000 rpm (SP-03, Taiwan), followed by rinsing with water several times to remove the remaining 
SDS. The optical transmittance of the MWCNT-PET film was controlled by the deposition time of ultrasonic atomization. Then, to enhance the electric flexibility and reinforce the mechanical properties of the film, $1.25 \mathrm{~mL}$ of the PVA water solution $(0.1 \%)$ was spun cast on top of the as-produced MWCNT-PET substrate. Finally, the PVA-coated MWCNT-PET film was hot pressed at a temperature of $80^{\circ} \mathrm{C}$ under a pressure of $100 \mathrm{~kg} / \mathrm{cm}^{2}$ for $30 \mathrm{~min}$ using a thermo-compression method (BM-HP-6000K, Taiwan). The resulting film possessed not only good mechanical flexibility but also excellent conductivity owing to its dense, compact structure.

\section{Results and discussions}

\subsection{Characterization of MWCNT dispersion}

For broad applications of MWCNTs, it is necessary that the MWCNT bundles are processed to form individually dispersed nanotubes prior to their use. SDS is extensively used for carbon nanotube dispersion by adsorbing onto nanotube surface via a noncovalent approach in which the higher charge in the head groups strengthens the electrostatic repulsion among surface-covered nanotubes, rendering them disaggregate thereby resulting in a more stable suspension. Figure 4 shows the solubility of the MWCNTs in a SDS aqueous solution with low concentration of $0.25 \mathrm{wt} \%$. It is clear that MWCNTs were not completely soluble in the SDS solution even after $8 \mathrm{~h}$ of sonication using the bath sonicator because sedimentation of the MWCNTs at the bottom of the bottle was observed (Figure 4a). Notably, by using high-energy probe type ultrasonication, the MWCNTs were entirely dispersed in the aqueous solution in the presence of SDS, forming a homogeneous-free solution (Figure 4b). Significantly, the observed MWCNT dispersions were stable without any sedimentation or aggregation of nanotubes bundles for at least two years. These results indicate that the high-energy probe type ultrasonication process combined with the assistance of SDS surfactant could be successfully used to obtain a stable and homogeneous MWCNT aqueous solution, even with a low SDS concentration.

In addition to the obvious difficulty in obtaining a stable and homogeneous solution of individual carbon nanotube suspensions, another complication is to find a valid method to evaluate their state and concentration in the solution, which is usually necessary for qualitative and quantitative analysis of the data. The optical absorption measurement has been employed for the determination of individual CNT solubility and dispersion limits, in which the absorption was strongly dependent on the amount of CNT dissolved in the solution. (Priya \& Byrne, 2008) Importantly, a linear fit between the absorption and CNT concentration was present, in accordance with Beer's law, and intersected at zero, indicating that the region consisted of significantly debundled CNTs. (Jeong et al., 2007; Priya \& Byrne, 2008; Rastogi et al., 2008) In Figure 5a, we present a series of black, macroscopically homogeneous MWCNT dispersions at different concentrations of 25, 12.5, 8.33, 6.25, 5.00, and $2.5 \mathrm{mg} / \mathrm{L}$ obtained by diluting the starting MWCNT dispersions, which were also applied to calibrate the solubility of MWCNTs by measuring the intensity of the absorption. Figure $5 \mathrm{~b}$ depicts the UV-vis spectra of MWCNTs with varying concentrations of nanotubes in SDS surfactant solutions. The absorption decreased with the decreasing concentration of MWCNT aqueous solutions and a linear relationship between them, following Beer's law, could be observed between 200 to $1200 \mathrm{~nm}$ (Figure 5c). This result indicates that the asprepared MWCNT aqueous solution had significantly individual SWCNTs and no effect could be associated with the concentration-dependent carbon nanotube aggregation. Thus, 
the concentration-dependent absorption spectroscopy can be used as an effective probe for the monitoring the aggregation state of CNTs in suspension. The suspension of individual MWCNTs was further confirmed by tapping-mode atomic force microscopy (AFM, Veeco DI-3100) and high-resolution transmission electron microscopy (HRTEM, JEOL JEM-2100F). AFM images (Figure 6a) show that the MWCNTs are almost present in the dispersions as single tubes with no bundles. The average diameter of these tubes measured by AFM was approximately $40 \mathrm{~nm}$, which is larger than that of the original synthetic MWCNTs. This was a result of the SDS surfactants wrapping around the nanotubes, resulting in them remaining well dispersed in water. HRTEM images (Figure 6b) also show that the probe ultrasonication-treated MWCNTs do not contain any metal/oxide catalyst. The images also showed that the bundled architectures of the suspended MWCNTs consisted of 10-15 concentric shells with inner and outer diameters of the nanotubes of 5 and $15 \mathrm{~nm}$, respectively, and the layers were separated by the graphitic distance. The selected-area electron diffraction (SAED) pattern of the debundled carbon nanotubes, which are inserted in Figure 6b, illustrates the degree of crystallinity.

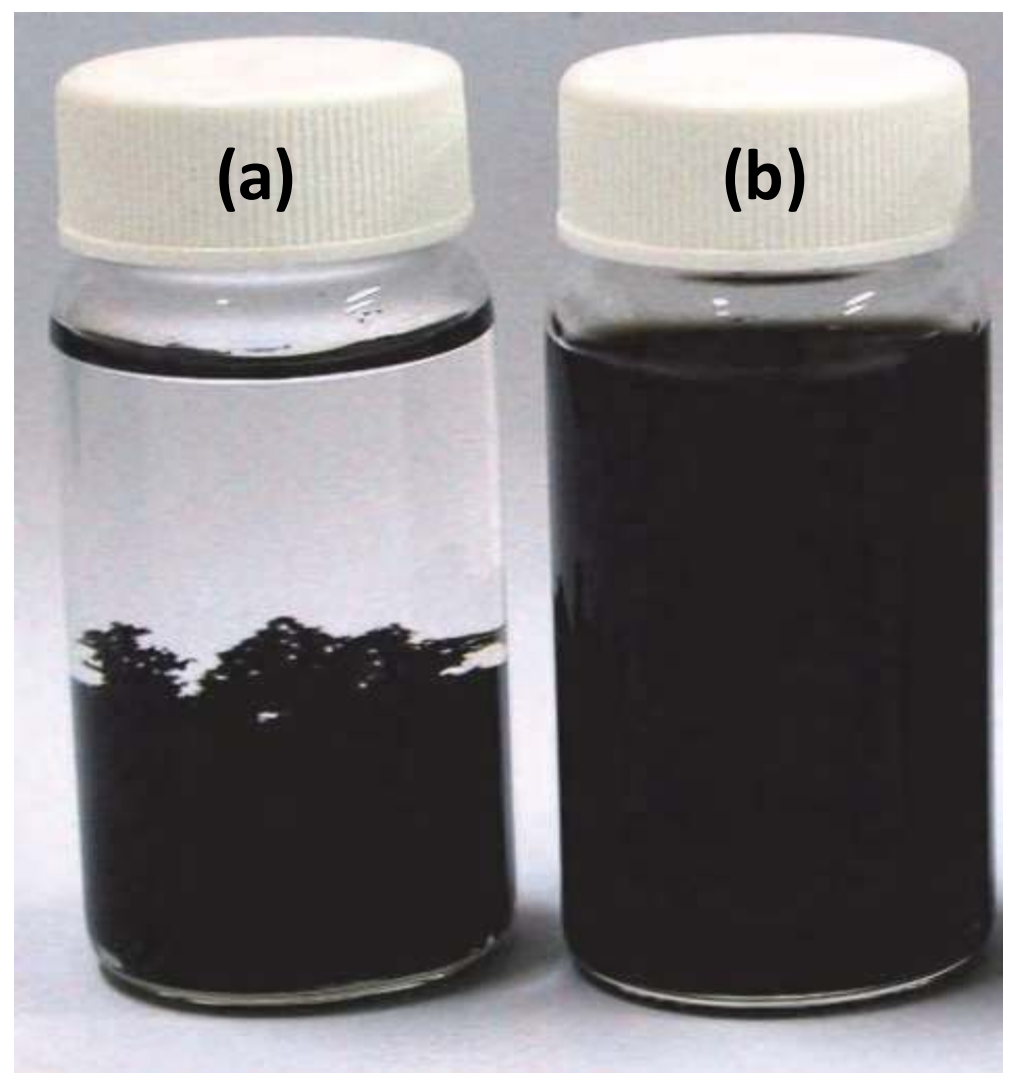

Fig. 4. Optical micrographs of MWCNTs dispersions in water in the presence of SDS surfactants prepared by means of (a) a bath sonication process for $8 \mathrm{~h}$ and (b) a high-energy probe type sonication process for $3 \mathrm{~min}$, respectively. 

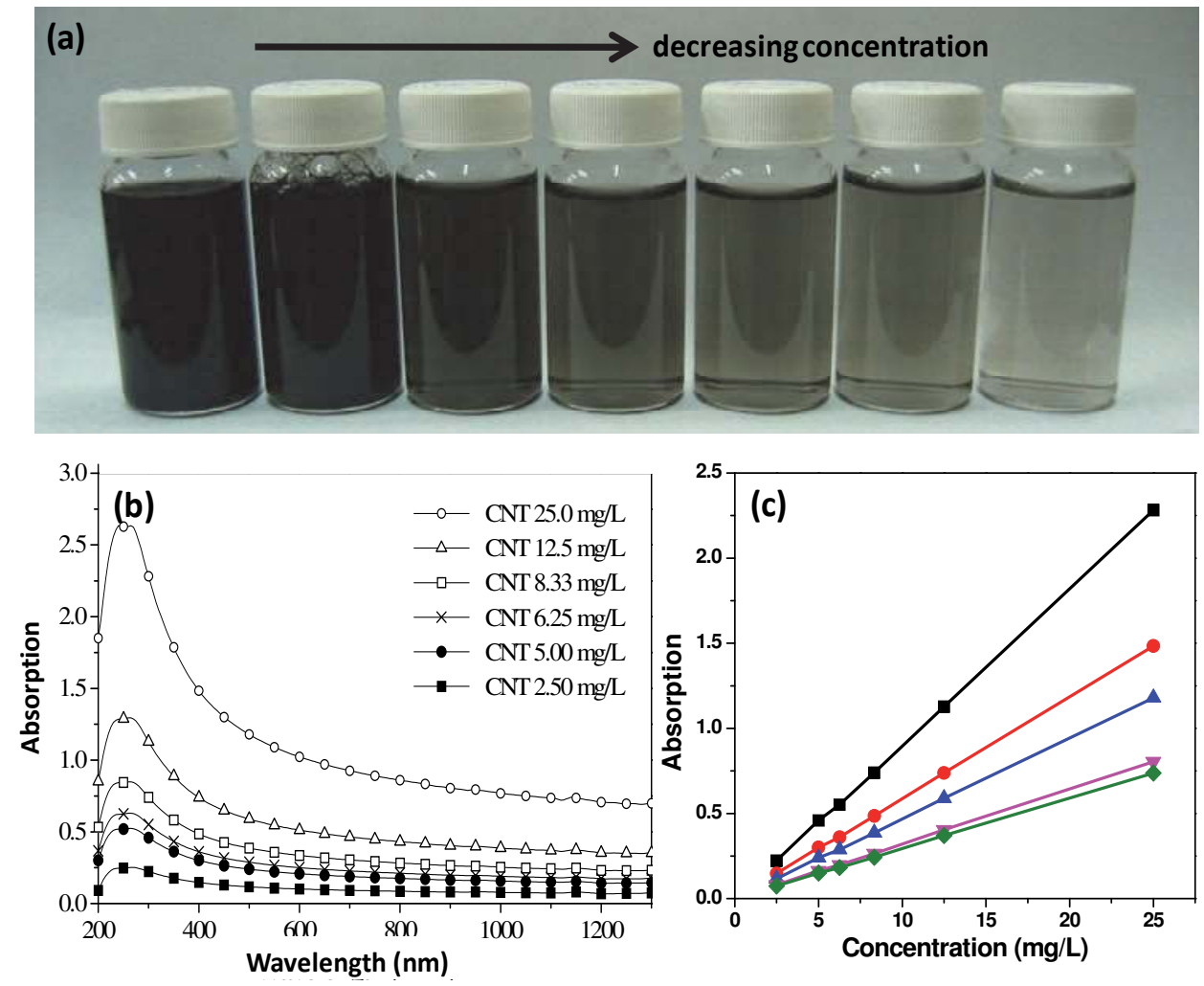

Fig. 5. (a) Optical micrograph of the MWCNT aqueous suspensions at different concentrations: $250 \mathrm{mg} / \mathrm{L}$ (starting MWCNT solution), $25.0 \mathrm{mg} / \mathrm{L}, 12.5 \mathrm{mg} / \mathrm{L}, 8.33 \mathrm{mg} / \mathrm{L}$, $6.25 \mathrm{mg} / \mathrm{L}, 5.00 \mathrm{mg} / \mathrm{L}$, and $2.50 \mathrm{mg} / \mathrm{L}$ in the presence of $0.25 \mathrm{wt} \% \mathrm{SDS}$ surfactant. (b) UVvis spectra recorded from an UV/Vis/NIR spectrometer (Perkin-Elmer Lamda 900) of the MWCNT aqueous solution at different concentrations in the presence of $0.25 \%$ SDS surfactant. (c) Absorption as a function of the concentration of the MWCNT aqueous solutions conducted at the wavelength of $(\boldsymbol{\bullet}) 300 \mathrm{~nm},(\bullet) 400 \mathrm{~nm},(\Delta) 500 \mathrm{~nm},(\boldsymbol{\nabla}) 900 \mathrm{~nm}$, and $(\diamond) 1100 \mathrm{~nm}$. The linear fits are forced through zero. 

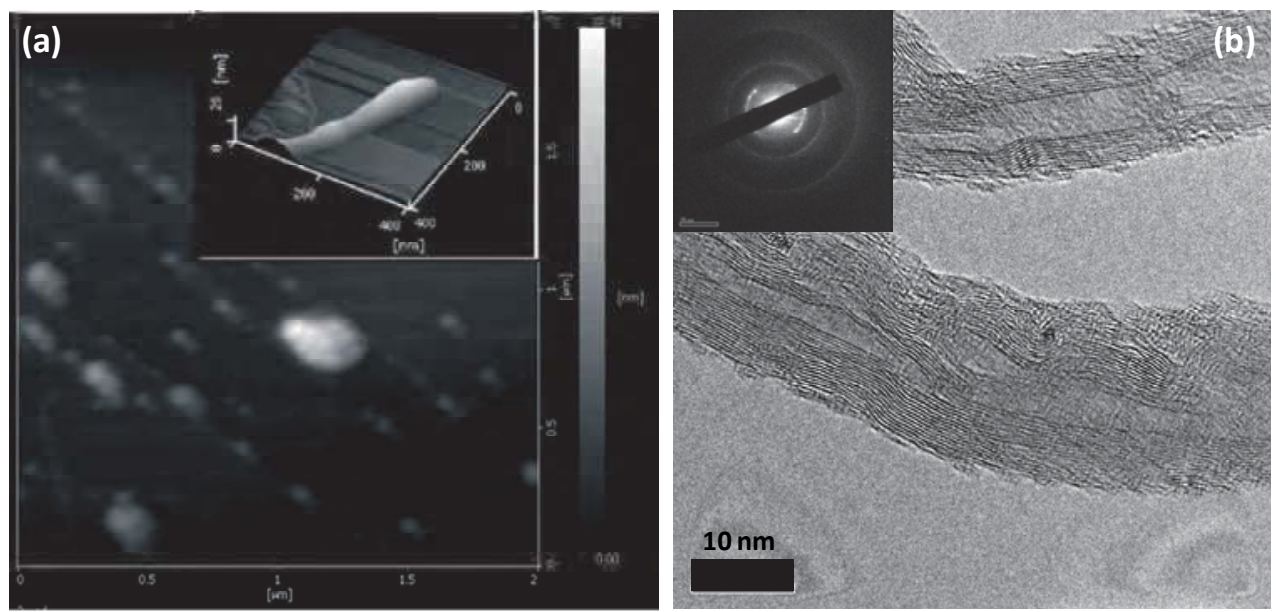

Fig. 6. (a) AFM images of the MWCNT aqueous solution with SDS surfactants. (b) HRTEM image of a MWCNT, which consisted of lattice finger walls. Inset shows the electron diffraction pattern of the carbon nanotube.

\subsection{MWCNT-based flexible transparent conducting thin film}

CNT-related films that possess porous geometries are of great interest as a class of structures owing to their unique intrinsic properties and potential scientific and technical applications in optoelectronic devices. (Motavas et al., 2009; Skrabalak \& Suslick, 2006; Ulbricht et al., 2007) The open porosity structure has great benefits in the fabrication of CNT-related films with both high transparency and good electrical conductivity as a result of the porosity cavities and intersecting nanotube networks. Herein, we report for the first time the successful formation of MWCNT TCFs with porous structures constructed from two different architectures, i.e., unusual open rings and a honeycomb network, through the use of the ultrasonic atomizer technique from the dispersing MWCNT aqueous solution.

\subsubsection{Open rings network-based MWCNT TCFs}

Open-rings of MWCNTs stacked to form porous networks onto a poly(ethylene terephthalate) (PET) substrate in the formation of a flexible conducting film with great electrical conductivity and transparency were generated by ultrasonic atomization combined with a spin-coating technique.

Large-scale, transparent and flexible PVA-coated MWCNT-PET thin films prepared at different ultrasonic atomization time were successfully obtained as shown in Figure 7, in which the PVA film provided an additional advantage for mechanical reinforcement of the MWCNT thin film. It is notable that the ultrasonic atomization time plays an important role in the optical transparency of the films. As the ultrasonic atomization proceeded, the transmittance of the films decreased, which is ascribed to the increasing amount of the MWCNTs deposited on the PET film. The effect of ultrasonic atomization time on the transmittance and electrical conductivity of the as-prepared films was further studied by a UV/Vis/NIR spectrometer (Perkin-Elmer Lamda 900) and four probe point system (SR-4, Everbeing), as shown in Figure 8. From Figure 8a, we could observe that the transmittance and electrical resistance of the films decreased with the increase of the reaction time. At 
early reaction times of approximately $5 \mathrm{~min}$, the MWCNT film exhibited the highest resistance of around $4 \mathrm{M} \Omega / \mathrm{sq}$ when the optical transmittance reached $93 \%$ at $550 \mathrm{~nm}$. After the deposition time of $15 \mathrm{~min}$, the sheet resistance dramatically decreased to $460 \Omega$ /sq with the optical transmittance of $89 \%$. The substantial decrease in sheet resistance is due to the efficient percolation paths for charge transport through the well-interconnected networks. (Hu et al., 2004) Subsequently, the sheet resistance dropped off to $\sim 200 \Omega / \mathrm{sq}$ at $120 \mathrm{~min}$, while the corresponding transmittance was observed to decreased to $69 \%$. The relationship of the optical transmittance at $550 \mathrm{~nm}$ and sheet resistance was plotted in Figure $8 \mathrm{~b}$.

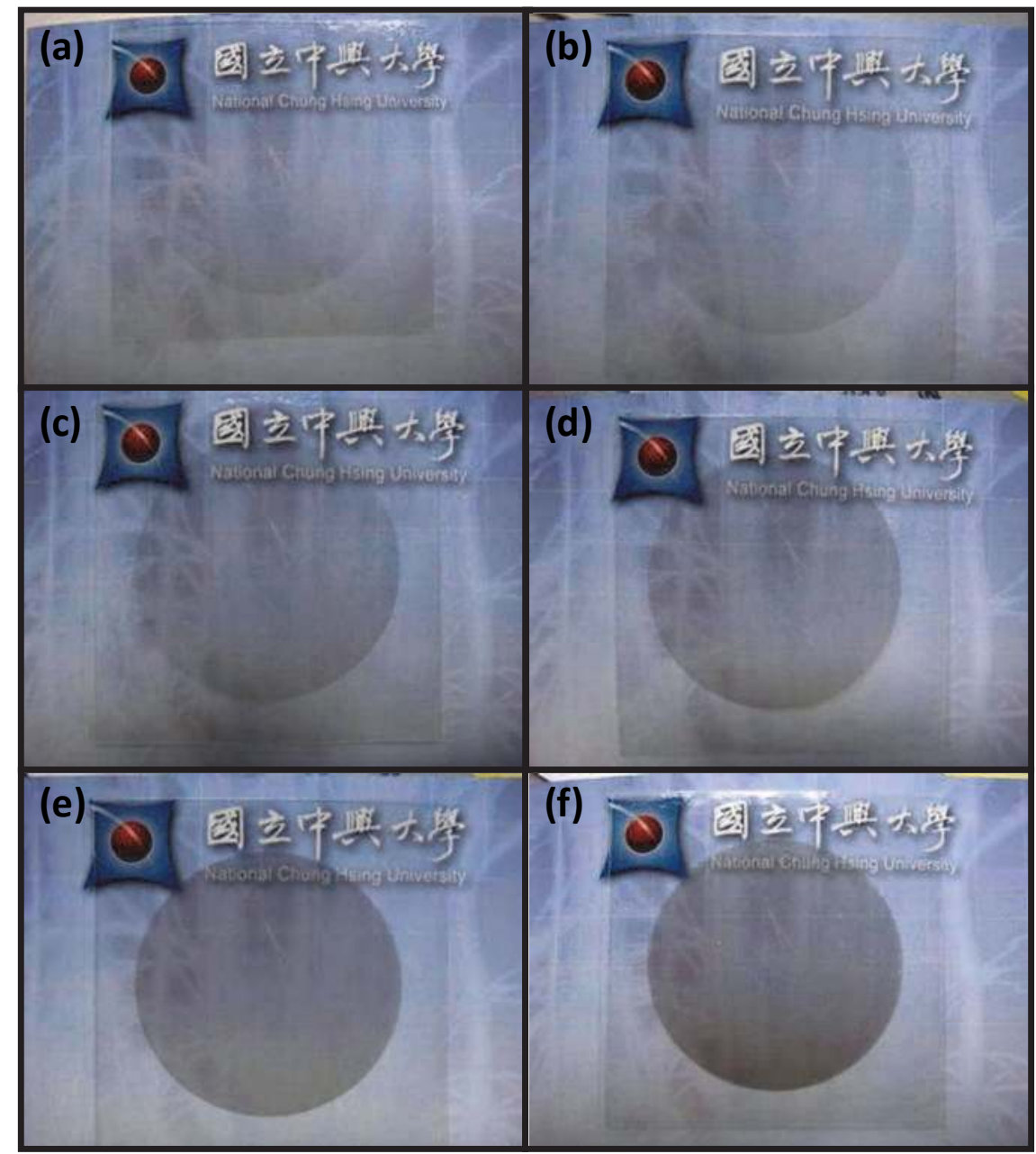

Fig. 7. (a) Photographs of the PVA-coated MWCNT-PET film prepared by ultrasonic atomization combined with the spin-coating technique with the aid of a thermo-compression method. The ultrasonic atomization time used for the preparation of the MWCNT-PET film was controlled at (a) $5 \mathrm{~min}$, (b) $15 \mathrm{~min}$, (c) $30 \mathrm{~min}$, (d) $45 \mathrm{~min}$, (e) $60 \mathrm{~min}$, and (e) $120 \mathrm{~min}$. 
With such excellent transparency and electrical conductivity properties, it is interesting to investigate the architecture stacked by MWCNTs onto the surface of PET films. Therefore, FESEM analysis was used to further study the architecture using a Zeiss URTRA 55 and JEOL JEM-7500F. Figure 9a and 9b show the FESEM images of the MWCNT-PET film prepared at the initial ultrasonic atomization time of $30 \mathrm{~s}$, which illustrates that the porous network structure of MWCNTs are randomly stacking by the overlapping and crossing the open rings which are with $80-100 \mu \mathrm{m}$ in diameter and $800 \mathrm{~nm}$ in wall width. This ring structure, constructed by the interaction of the droplet gravity, liquid surface tension, and centrifuge force during the atomization process, was quite suitable for making transparent conducting films. (Qiao \& Chandra, 1996) It is important to note that the wall of the open rings was constructed from individual MWCNTs (Figure 9c), which have long persistence lengths and are naturally interconnected and entangled with each other by van der Waals forces to form intersecting points and a spider web-like structure within the wall structure, leading to a robust conducting open-ring. They were further interconnected in the assembly to make a porous network that can permit fast charge transport between the interconnection conducting paths of wall structures and achieve high optical transparency because of the well-developed porous structures.
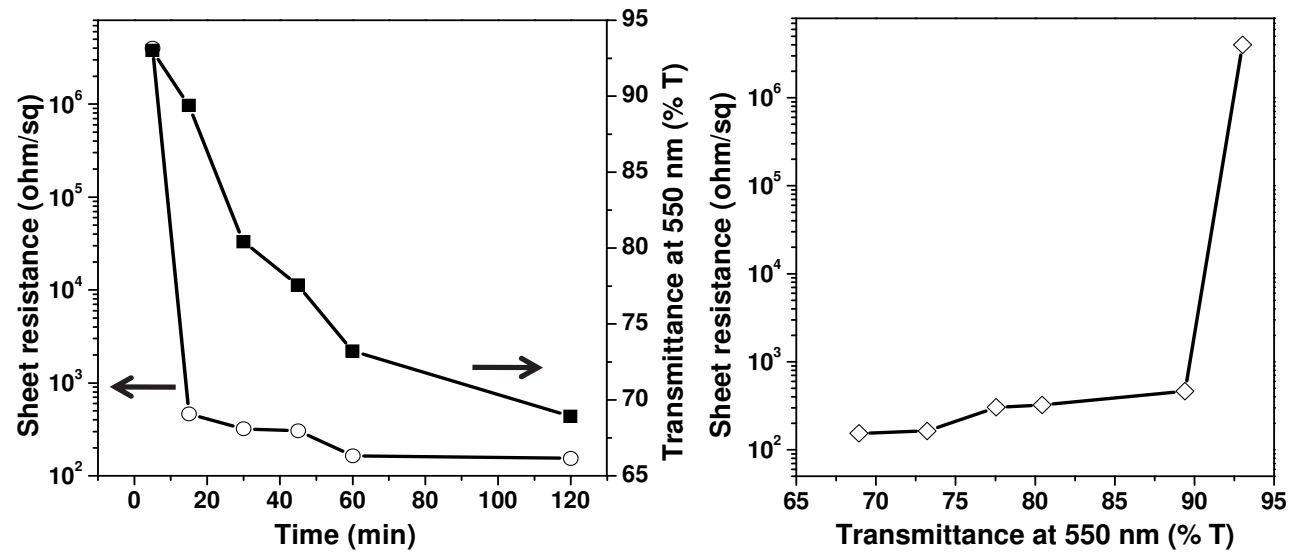

Fig. 8. (a) Optical transmittance (at $550 \mathrm{~nm}, \mathbf{\square}$ ) and sheet resistance (o) of the MWCNT-PET thin film, as a function of the time of ultrasonic atomization. (b) Transmittance vs. resistance of the as-produced MWCNT-PET at the ultrasonic atomization time of $120 \mathrm{~min}, 60 \mathrm{~min}$, 45min, $30 \mathrm{~min}, 15 \mathrm{~min}$, and $5 \mathrm{~min}$ (from left to right).

To further explore the feasibility of these open ring network-based MWCNT TCFs, we analyzed the strain-dependent electrical resistance characteristics of the films with and without the incorporation of PVA thin films by a two-point bending test. Representative results are presented in Figure 10. Figure 10b reveals the sheet resistance versus the flexing cycles for the representative MWCNT-PET without coating the PVA film. It was found that the sheet resistance dramatically increased by more than 30 times after bending and then gradually recovered after relaxation, which is due to the fact that the van der Waals interactions are strong enough to maintain the porous network structure. In addition, small changes could be observed after 3 bending cycles. The sheet resistances are maintained at ca. 

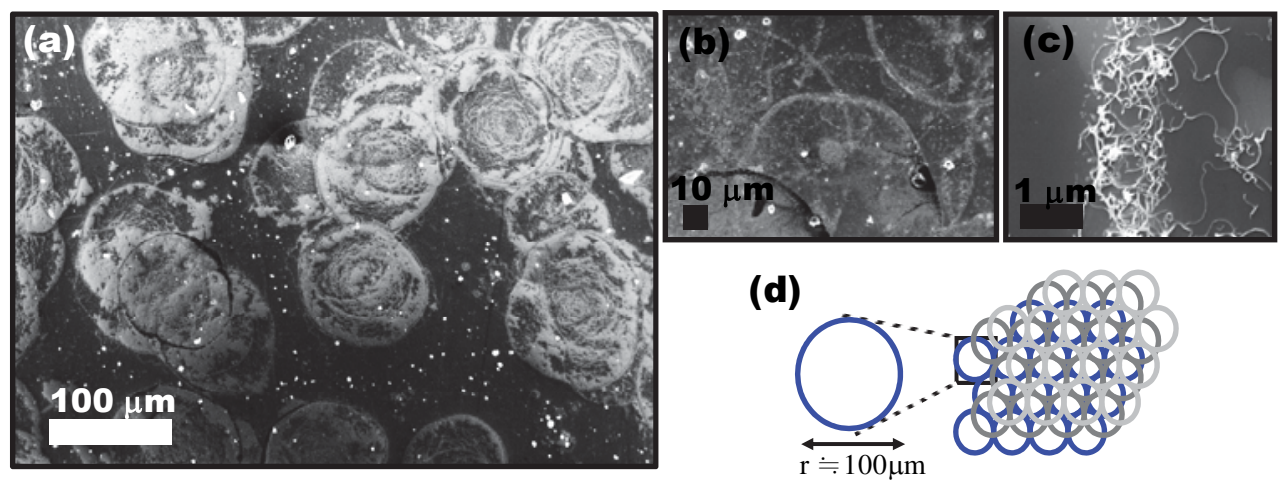

Fig. 9. FESEM images of open-rings of MWCNTs on a PET substrate (a) before and (b) after the removal of SDS. The time of ultrasonic atomization was $30 \mathrm{~s}$. (c) One part of wall of the selected ring. (d) Schematic formation of the porous MWCNT network by the open-rings structure.

(a)
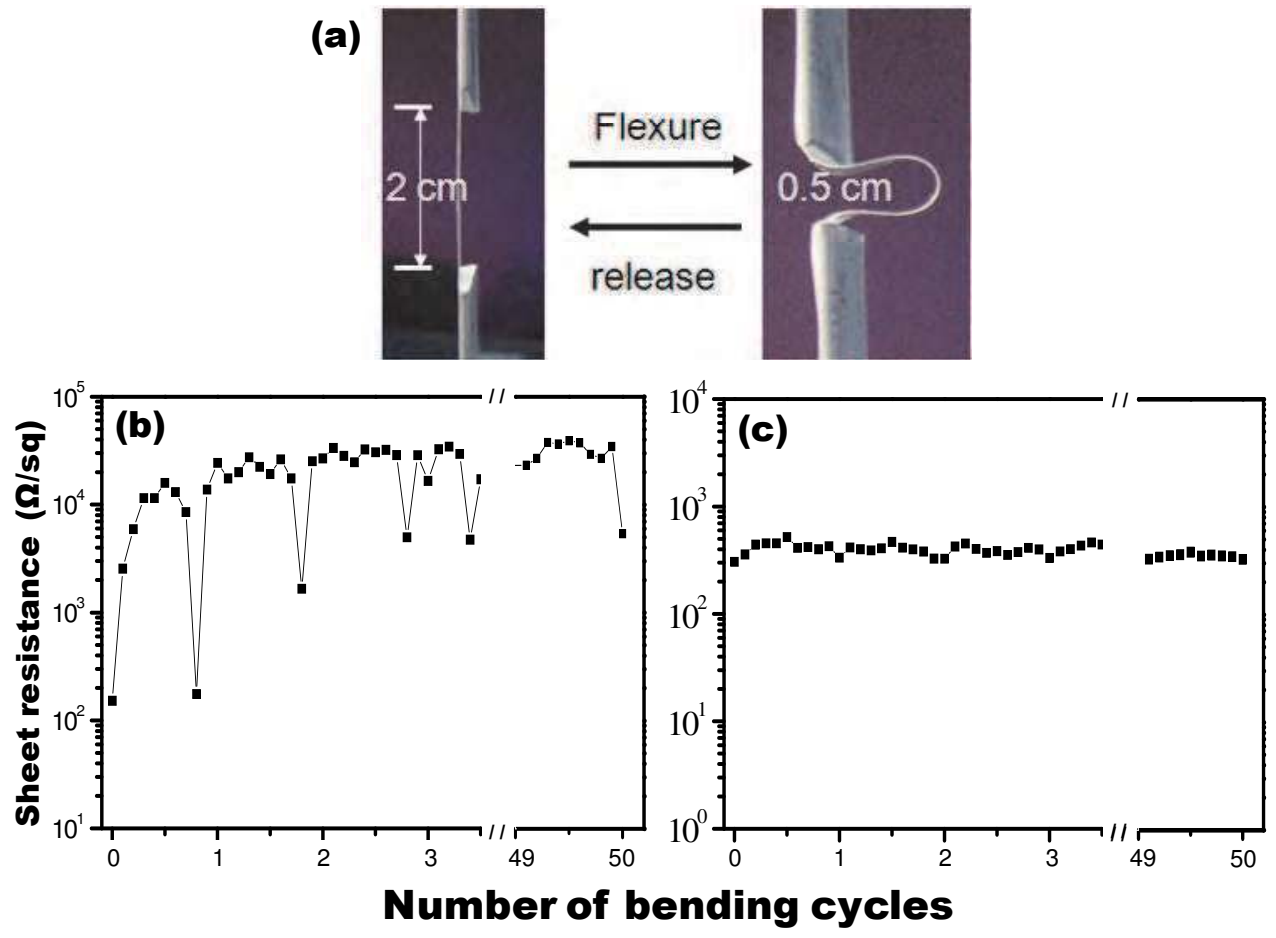

Fig. 10. (a) Schematic graph of the two-point bending test for the generated MWCNT-based thin film. Changes in sheer resistance of the (a) as-produced MWCNT-PET thin film and (b) the PVA-enhanced film during repeated bending. 
$3700( \pm 1 \%) \mathrm{ohm} / \mathrm{sq}$ with complete recovery after bending. This observation illustrates that the flexibility of MWCNT films is quite reliable, but the electric conductivity does not meet the criteria necessary for practical touch screen application (sheet resistance $<500 \mathrm{ohm} / \mathrm{sq}$ ). The increased resistance of the MWCNT thin films can be attributed to the change of contact resistance among carbon nanotubes and pressure-induced changes in the band gap of carbon nanotubes, even though as a whole it remains conductive. (Cao et al., 2007) Interestingly, relatively small changes were observed in sheet resistance during the bending of the PVAcoated MWCNT-PET thin film, which possessed around $360 \mathrm{ohm} / \mathrm{sq}$ after bending 50 times (Figure 10c). Most importantly, there is no significant degradation in conductivity even after 500 bending cycles where the sheet resistances remained approximately $370( \pm 3 \%) \mathrm{ohm} / \mathrm{sq}$. Besides, a splendid transparency remained with the transmittance of around $77 \%$ at $550 \mathrm{~nm}$ (not shown). The result illustrates that the produced thin films have a robust flexibility and do not break/crack upon bending and relaxing, meaning they can be rolled and unrolled repeatedly with no impact to their transparency and conductivity. This result indicates the PVA-coated open-rings MWCNT thin film could be considered as an alternative for optoelectronic device applications such as FETs, sensors, and touch screens.

\subsubsection{Two-dimensional honeycomb network-based MWCNT TCFs}

Another porous carbon materials film constructed with a quasi-honeycomb network was also generated by our continuous and one-step spin-coating method combined with ultrasonic atomization to the as-prepared MWCNT-SDS supernatant solution by tuning some experimental parameters.(Su et al., 2008) A quasi-honeycomb framework built up through carbon nanotube wires was observed after the removal of the surfactant of SDS, as shown in Figure 11a. The individual CNT "sticks" are connected with each other through van der Waals interactions to form one-dimensional conducting wires, which have long persistence lengths and tend to entangle to form intersecting points in the networks. These conducting sticks play an important role in the electric properties of CNT networks, where the larger the nanowire conductivity, the better the network conductance. With such a unique honeycomb network formed by interconnected individual CNT sticks, we could expect that the two-dimensional honeycomb network-based MWCNT TCFs have good transparency and electrical conductivity. Figure $11 \mathrm{~b}$ shows that this level of porosity of the honeycomb network-based MWCNT TCFs is consistent with its optical properties, with ultra-high film transmittance $>85 \%$ over the visible part of the spectrum. Moreover, there is no difference in the analysis of optical transmittance for this representative CNT film, indicating that the size of homogeneous honeycomb structure is up to $4 \times 4 \mathrm{~cm}^{2}$. The corresponding sheet resistance can reach $500 \mathrm{ohm} / \mathrm{sq}$ (using a four probe point stand equipment), which is comparable to that of SWCNTS and ITO materials on PET substrates. (Dettlaff-Weglikowska et al., 2005; Geng et al., 2007; Hu et al., 2004) According to the excellent optical and electrical properties, the conducting honeycomb CNT films should present new opportunities for the development of next-generation flexible touch screens.

\section{Conclusion}

The present invention provides a method for the rapid dispersion of CNTs in an aqueous solution with the aid of nontoxic surfactants through a novel, simple, fast, and inexpensive sonophysically exfoliated method. In this method, the carbon nanotubes are added to an aqueous solution of a nontoxic surfactant, and then dispersed therein through ultrasonic 
oscillation. Importantly, this uniform dispersion can last stably for at least two years without aggregation, suspension, or precipitation. This dispersion is suitable for calibrating the concentration of the carbon nanotubes. Further, the as-prepared dispersed MWCNT aqueous solution could be successfully further used for making MWCNT TCFs with porous carbon nanotubes frameworks onto the surface of PET films through the spin-coating method combined with ultrasonic atomization. Two types of the porous structures were achieved: open rings and a honeycomb network. This approach is straightforward for a large-sized film. Importantly, compared with other MWCNT-based transparent thin films, (Castro \& Schmidt, 2008; de Andrade et al., 2007; Havel et al., 2008; Kaempgen et al., 2005) this process dramatically improved the electrical conductivity for transmittance in the range of $\sim 65 \%-85 \%$ in both of these systems, as shown in Figure 12. Furthermore, we find that the coating of the ultrathin PVA film provides an additional advantage for the enhancement of the electric flexibility and reinforcement of the mechanical property of the film. Thus, because of the ease of use and low implementation cost of the ultrasonic atomization-spin coating process, our approach could provide a straightforward technique for large-sized transparent conducting film production and open new opportunities for the development of next-generation flexible touch screens and porous carbon nanotube-based electrodes.
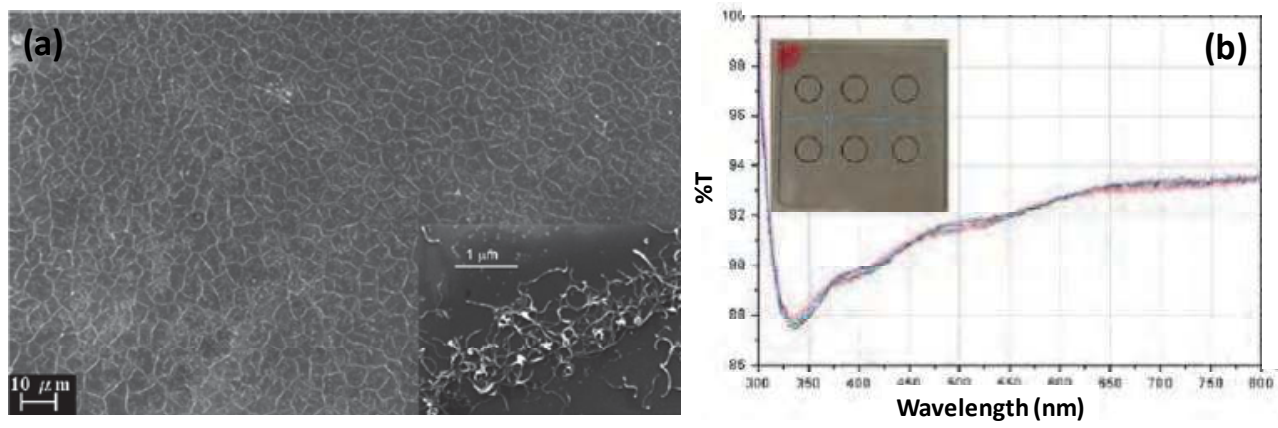

Fig. 11. (a) FE-SEM image of the morphology of honeycomb networks constructed from pure CNT wires. Inset: one selected wall of the CNT network. (b) UV-Vis spectra for the honeycomb CNT film, showing good transparency on the homogenous uniform film $(4 \times 4$ $\mathrm{cm}^{2}$ ). Six selected optical spectra on the circles were taken (Inset). 


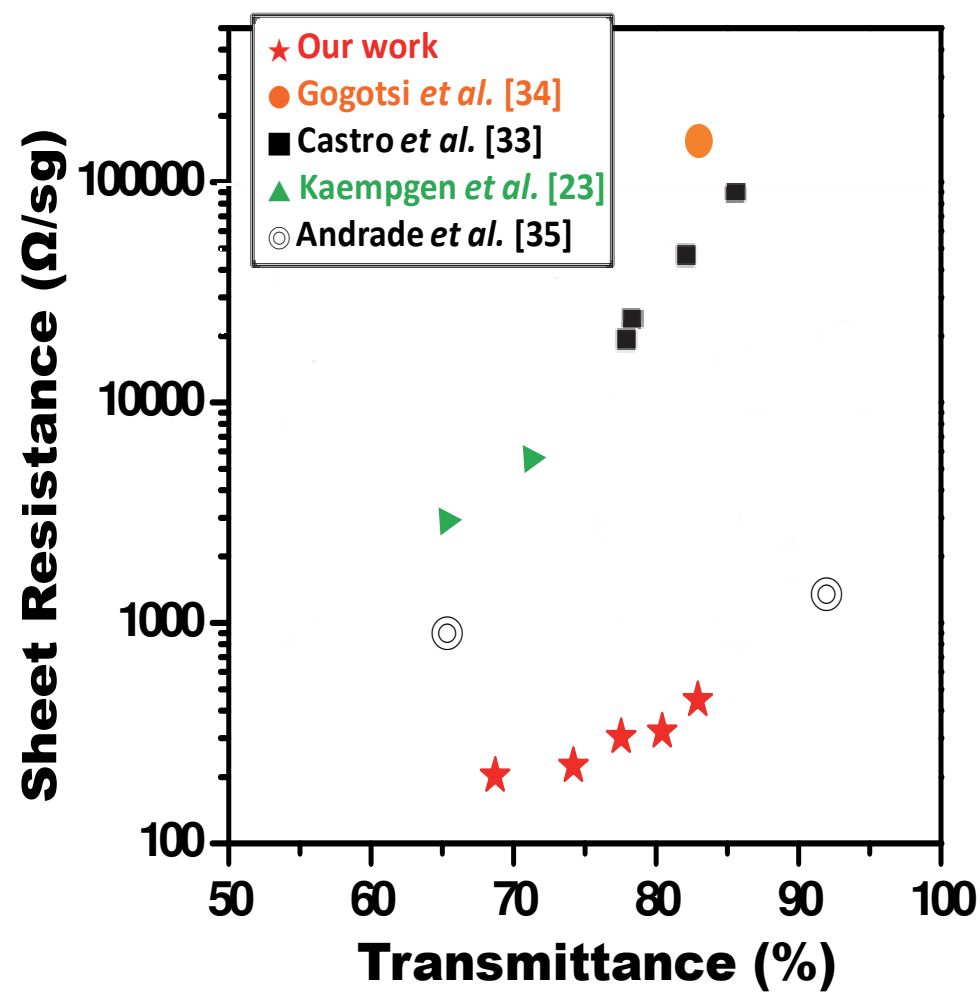

Fig. 12. Comparison of the sheet resistance of our open-ring MWCNT-PET thin films with other MWCNT-based thin films reported in the literature, as a function of transmittance at $550 \mathrm{~nm}$.

\section{Acknowledgement}

We gratefully acknowledge the support through the National Science Council of Taiwan, Republic of China, under project NSC-98-2113-M-005-004-MY3 and NSC-98-2120-M-007-009.

\section{References}

Calnan, S. \& Tiwari, A. N. (2010). High mobility transparent conducting oxides for thin film solar cells. Thin Solid Films, 518(7), 1839-1849.

Cao, C. L.; Hu, C. G.; Xiong, Y. F.; Han, X. Y.; Xi, Y. \& Miao, J. (2007). Temperature dependent piezoresistive effect of multi-walled carbon nanotube films. Diam. Relat. Mat., 16(2), 388-392.

Castro, M. R. S. \& Schmidt, H. K. (2008). Preparation and characterization of low- and highadherent transparent multi-walled carbon nanotube thin films. Mater. Chem. Phys., 111(2-3), 317-321. 
Chen, P. C.; Chen, H. T.; Qiu, J. \& Zhou, C. W. Inkjet Printing of Single-Walled Carbon Nanotube/RuO2 Nanowire Supercapacitors on Cloth Fabrics and Flexible Substrates. Nano Research, 3(8), 594-603.

Dan, B.; Irvin, G. C. \& Pasquali, M. (2009). Continuous and Scalable Fabrication of Transparent Conducting Carbon Nanotube Films. Acs Nano, 3(4), 835-843.

de Andrade, M. J.; Lima, M. D.; Skakalova, V.; Bergmann, C. P. \& Roth, S. (2007). Electrical properties of transparent carbon nanotube networks prepared through different techniques. Phys. Stat. Sol. (RRL), 1, 178-180.

Dettlaff-Weglikowska, U.; Skakalova, V.; Graupner, R.; Jhang, S. H.; Kim, B. H.; Lee, H. J., et al. (2005). Effect of SOCl2 treatment on electrical and mechanical properties of single-wall carbon nanotube networks. Journal of the American Chemical Society, 127, 5125-5131.

Feng, C.; Liu, K.; Wu, J. S.; Liu, L.; Cheng, J. S.; Zhang, Y. Y., et al. (2010). Flexible, Stretchable, Transparent Conducting Films Made from Superaligned Carbon Nanotubes. Advanced Functional Materials, 20(6), 885-891.

Geng, H. Z.; Kim, K. K.; So, K. P.; Lee, Y. S.; Chang, Y. \& Lee, Y. H. (2007). Effect of acid treatment on carbon nanotube-based flexible transparent conducting films. Journal of the American Chemical Society, 129(25), 7758-+.

Girifalco, L. A.; Hodak, M. \& Lee, R. S. (2000). Carbon nanotubes, buckyballs, ropes, and a universal graphitic potential. Physical Review B, 62(19), 13104-13110.

Gruner, G. (2006). Carbon nanotube films for transparent and plastic electronics. Journal of Materials Chemistry, 16(35), 3533-3539.

Havel, M.; Behler, K.; Korneva, G. \& Gogotsi, Y. (2008). Transparent thin films of multiwalled carbon nanotubes self-assembled on polyamide 11 nanofibers. Advanced Functional Materials, 18(16), 2322-2327.

Heo, G. S.; Matsumoto, Y.; Gim, I. G.; Lee, H. K.; Park, J. W. \& Kim, T. W. (2010). Transparent conducting amorphous $\mathrm{Zn}-\mathrm{In}-\mathrm{Sn}-\mathrm{O}$ anode for flexible organic lightemitting diodes. Solid State Communications, 150(3-4), 223-226.

Hu, L.; Hecht, D. S. \& Gruner, G. (2004). Percolation in transparent and conducting carbon nanotube networks. Nano Letters, 4(12), 2513-2517.

Jeong, S. H.; Kim, K. K.; Jeong, S. J.; An, K. H.; Lee, S. H. \& Lee, Y. H. (2007). Optical absorption spectroscopy for determining carbon nanotube concentration in solution. Synthetic Metals, 157, 570-574.

Jo, G.; Choe, M.; Cho, C. Y.; Kim, J. H.; Park, W.; Lee, S., et al. (2010). Large-scale patterned multi-layer graphene films as transparent conducting electrodes for GaN lightemitting diodes. Nanotechnology, 21(17), 175201.

Kaempgen, M.; Duesberg, G. S. \& Roth, S. (2005). Transparent carbon nanotube coatings. Applied Surface Science, 252(2), 425-429.

Kim, D. H.; Park, M. R.; Lee, H. J. \& Lee, G. H. (2006). Thickness dependence of electrical properties of ITO film deposited on a plastic substrate by RF magnetron sputtering. Applied Surface Science, 253(2), 409-411.

Kim, O. K.; Je, J. T.; Baldwin, J. W.; Kooi, S.; Pehrsson, P. E. \& Buckley, L. J. (2003). Solubilization of single-wall carbon nanotubes by supramolecular encapsulation of helical amylose. Journal of the American Chemical Society, 125(15), 4426-4427. 
Li, D.; Wang, H. Z.; Zhu, J. W.; Wang, X.; Lu, L. D. \& Yang, X. J. (2003). Dispersion of carbon nanotubes in aqueous solutions containing poly(diallyldimethylammonium chloride). Journal of Materials Science Letters, 22(4), 253-255.

Li, Z. R.; Kandel, H. R.; Dervishi, E.; Saini, V.; Biris, A. S.; Biris, A. R., et al. (2007). Does the wall number of carbon nanotubes matter as conductive transparent material? Applied Physics Letters, 91(5), 053115.

Lin, Y. C.; Li, J. Y. \& Yen, W. T. (2008). Low temperature ITO thin film deposition on PES substrate using pulse magnetron sputtering. Applied Surface Science, 254(11), 32623268 .

Lu, K. L.; Lago, R. M.; Chen, Y. K.; Green, M. L. H.; Harris, P. J. F. \& Tsang, S. C. (1996). Mechanical damage of carbon nanotubes by ultrasound. Carbon, 34(6), 814-816.

Madni, I.; Hwang, C. Y.; Park, S. D.; Choa, Y. H. \& Kim, H. T. (2010). Mixed surfactant system for stable suspension of multiwalled carbon nanotubes. Colloids and Surfaces a-Physicochemical and Engineering Aspects, 358(1-3), 101-107.

Manivannan, S.; Ryu, J. H.; Lim, H. E.; Nakamoto, M.; Jang, J. \& Park, K. C. (2010). Properties of surface treated transparent conducting single walled carbon nanotube films. Journal of Materials Science-Materials in Electronics, 21(1), 72-77.

Marsh, D. H.; Rance, G. A.; Zaka, M. H.; Whitby, R. J. \& Khlobystov, A. N. (2007). Comparison of the stability of multiwalled carbon nanotube dispersions in water. Physical Chemistry Chemical Physics, 9, 5490-5496.

Miller, D. L. (1984). Gas body activation. Ultrasonics, 22(6), 259-260.

Motavas, S.; Omrane, B. \& Papadopoulos, C. (2009). Large-Area Patterning of Carbon Nanotube Ring Arrays. Langmuir, 25(8), 4655-4658.

Na, S. I.; Kim, S. S.; Jo, J. \& Kim, D. Y. (2008). Efficient and Flexible ITO-Free Organic Solar Cells Using Highly Conductive Polymer Anodes. Advanced Materials, 20(21), 40614017.

Paloniemi, H.; Aaritalo, T.; Laiho, T.; Liuke, H.; Kocharova, N.; Haapakka, K., et al. (2005). Water-soluble full-length single-wall carbon nanotube polyelectrolytes: Preparation and characterization. Journal of Physical Chemistry B, 109(18), 8634-8642.

Park, H.; Kim, J. S.; Choi, B. G.; Jo, S. M.; Kim, D. Y.; Hong, W. H., et al. (2010). Sonochemical hybridization of carbon nanotubes with gold nanoparticles for the production of flexible transparent conducing films. Carbon, 48(5), 1325-1330.

Paul, S. \& Kim, D. W. (2009). Preparation and characterization of highly conductive transparent films with single-walled carbon nanotubes for flexible display applications. Carbon, 47(10), 2436-2441.

Priya, B. R. \& Byrne, H. J. (2008). Investigation of sodium dodecyl benzene sulfonate assisted dispersion and debundling of single-wall carbon nanotubes. Journal of Physical Chemistry C, 112(2), 332-337.

Qiao, Y. M. \& Chandra, S. (1996). Boiliing of droplets on a hot surface in low gravity. lnt. J. Heat Mass Transfer, 39(7), 1379-1393.

Rastogi, R.; Kaushal, R.; Tripathi, S. K.; Sharma, A. L.; Kaur, I. \& Bharadwaj, L. M. (2008). Comparative study of carbon nanotube dispersion using surfactants. Journal of Colloid and Interface Science, 328(2), 421-428.

Saran, N.; Parikh, K.; Suh, D. S.; Munoz, E.; Kolla, H. \& Manohar, S. K. (2004). Fabrication and characterization of thin films of single-walled carbon nanotube bundles on 
flexible plastic substrates. Journal of the American Chemical Society, 126(14), 44624463.

Sierros, K. A.; Morris, N. J.; Kukureka, S. N. \& Cairns, D. R. (2009). Dry and wet sliding wear of ITO-coated PET components used in flexible optoelectronic applications. Wear, 267(1-4), 625-631.

Simien, D.; Fagan, J. A.; Luo, W.; Douglas, J. F.; Migler, K. \& Obrzut, J. (2008). Influence of nanotube length on the optical and conductivity properties of thin single-wall carbon nanotube networks. Acs Nano, 2(9), 1879-1884.

Skrabalak, S. E. \& Suslick, K. S. (2006). Porous carbon powders prepared by ultrasonic spray pyrolysis. Journal of the American Chemical Society, 128(39), 12642-12643.

$\mathrm{Su}$, J. W.; Fu, S. J.; Gwo, S. \& Lin, K. J. (2008). Fabrication of porous carbon nanotube network. Chemical Communications(43), 5631-5632.

Su, J. W.; Hsu, C. Y.; Fu, S. J.; Guo, C. H. \& Lin, K. J. (2009). Sonophysically-Exfoliated Individual Multi-Walled Carbon Nanotubes in Water Solution. J. Chin. Chem. Soc., 56(5), 935-939.

Takenobu, T.; Takahashi, T.; Kanbara, T.; Tsukagoshi, K.; Aoyagi, Y. \& Iwasa, Y. (2006). High-performance transparent flexible transistors using carbon nanotube films. Applied Physics Letters, 88(3), 033511.

Thiruvengadathan, R.; Levi-Kalisman, Y. \& Regev, O. (2007). Synergetic effect of ultrasound and sodium dodecyl sulphate in the formation of $\mathrm{CdS}$ nanostructures in aqueous solution. Ultrasonics Sonochemistry, 14(3), 398-404.

Ulbricht, R.; Lee, S. B.; Jiang, X. M.; Inoue, K.; Zhang, M.; Fang, S. L., et al. (2007). Transparent carbon nanotube sheets as 3-D charge collectors in organic solar cells. Sol. Energy Mater. Sol. Cells, 91(5), 416-419.

Wang, L. M.; Chen, Y. J. \& Liao, J. W. (2008). Characteristics of indium-tin oxide thin films grown on flexible plastic substrates at room temperature. Journal of Physics and Chemistry of Solids, 69(2-3), 527-530.

Xiao, G. Z.; Tao, Y.; Lu, J. P. \& Zhang, Z. Y. (2010). Highly conductive and transparent carbon nanotube composite thin films deposited on polyethylene terephthalate solution dipping. Thin Solid Films, 518(10), 2822-2824.

Xu, G. H.; Zhang, Q.; Zhou, W. P.; Huang, J. Q. \& Wei, F. (2008). The feasibility of producing MWCNT paper and strong MWCNT film from VACNT array. Applied Physics aMaterials Science \& Processing, 92(3), 531-539.

Zhang, M.; Fang, S. L.; Zakhidov, A. A.; Lee, S. B.; Aliev, A. E.; Williams, C. D., et al. (2005). Strong, transparent, multifunctional, carbon nanotube sheets. Science, 309(5738), 1215-1219. 


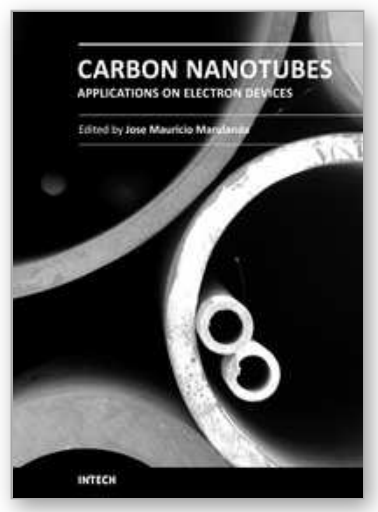

\section{Carbon Nanotubes Applications on Electron Devices}

Edited by Prof. Jose Mauricio Marulanda

ISBN 978-953-307-496-2

Hard cover, 556 pages

Publisher InTech

Published online 01, August, 2011

Published in print edition August, 2011

Carbon nanotubes (CNTs), discovered in 1991, have been a subject of intensive research for a wide range of applications. In the past decades, although carbon nanotubes have undergone massive research, considering the success of silicon, it has, nonetheless, been difficult to appreciate the potential influence of carbon nanotubes in current technology. The main objective of this book is therefore to give a wide variety of possible applications of carbon nanotubes in many industries related to electron device technology. This should allow the user to better appreciate the potential of these innovating nanometer sized materials. Readers of this book should have a good background on electron devices and semiconductor device physics as this book presents excellent results on possible device applications of carbon nanotubes. This book begins with an analysis on fabrication techniques, followed by a study on current models, and it presents a significant amount of work on different devices and applications available to current technology.

\section{How to reference}

In order to correctly reference this scholarly work, feel free to copy and paste the following:

Wen-Yin Ko, Jun-Wei Su and Kuan-Jiuh Lin (2011). Sonophysically Exfoliated Individual Multi-Walled Carbon Nanotubes in Water Solution and Their Straightforward Route to Flexible Transparent Conductive Films, Carbon Nanotubes Applications on Electron Devices, Prof. Jose Mauricio Marulanda (Ed.), ISBN: 978-953307-496-2, InTech, Available from: http://www.intechopen.com/books/carbon-nanotubes-applications-onelectron-devices/sonophysically-exfoliated-individual-multi-walled-carbon-nanotubes-in-water-solution-andtheir-strai

\section{INTECH}

open science | open minds

\section{InTech Europe}

University Campus STeP Ri

Slavka Krautzeka 83/A

51000 Rijeka, Croatia

Phone: +385 (51) 770447

Fax: +385 (51) 686166

www.intechopen.com

\section{InTech China}

Unit 405, Office Block, Hotel Equatorial Shanghai

No.65, Yan An Road (West), Shanghai, 200040, China 中国上海市延安西路65号上海国际贵都大饭店办公楼 405 单元

Phone: +86-21-62489820

Fax: +86-21-62489821 
(C) 2011 The Author(s). Licensee IntechOpen. This chapter is distributed under the terms of the Creative Commons Attribution-NonCommercialShareAlike-3.0 License, which permits use, distribution and reproduction for non-commercial purposes, provided the original is properly cited and derivative works building on this content are distributed under the same license. 